\title{
Formation and properties of L-arginine acetate single crystals doped with hydrochloric acid
}

\author{
P.V. Radhika ${ }^{1}$, K. Jayakumari ${ }^{2}$, C.K. Mahadevan ${ }^{3}$ \\ ${ }^{I}$ Department of Physics, Lekshmipuram College of Arts \& Science, Neyyoor-629802, Tamilnadu, India. \\ ${ }^{2}$ Department of Physics, Sree Ayyappa College for Women, Chunkankadai-629003, Tamilnadu, India. \\ ${ }^{3}$ Physics Research Centre, S.T. Hindu College, Nagercoil-629002, Tamilnadu, India.
}

\begin{abstract}
L-Arginine acetate (LAA) single crystals belonging to the amino acid group are reported to have promising NLO properties. In the present study, to improve further the characteristics of LAA crystals, $\mathrm{HCl}$ acid was incorporated into the crystal matrix as a dopant. Single crystals of pure and $\mathrm{HCl}$ doped LAA (a total of five) were grown successfully by using the slow evaporation technique. The grown crystals were confirmed chemically and structurally by performing X-ray diffraction (single crystal and powder), CHNS elemental, energy dispersive X-ray spectral and Fourier transform infrared spectral analyses. The crystals are found to be thermally stable up to $204{ }^{\circ} \mathrm{C}$. The UV-Vis spectral analysis shows that these crystals have wide transparency range in the entire visible region. Second harmonic generation ( $S H G)$ measurement shows the NLO property. Microhardness measurement indicates that the grown crystals come under soft material category. Dielectric measurements were carried out at various temperatures ranging from $40-140{ }^{\circ} \mathrm{C}$ and with various frequencies such as 1,10 and $100 \mathrm{kHz}$ by the parallel plate capacitor method. The AC activation energies were also determined. The temperature and frequency dependences of dielectric parameters observed indicate a normal dielectric behavior for all the five crystals grown in the present study.
\end{abstract}

Key words: L-arginine acetate, crystal growth, slow evaporation technique, doping effect, physical properties

\section{Introduction}

Amino acids are strong candidates for optical SHG because they contain chiral carbon atom and crystallize in non-centrosymmetric space groups. Recent studies reveal that L-arginine acetate (LAA), belonging to the amino acid group, possesses excellent optical, thermal and mechanical properties, which make it a strong candidate for photonic device applications [1-3].

A considerable interest has been shown recently in studying the effect of impurities (both organic and inorganic) on the nucleation, growth and physical properties of some hydrogen bonded crystals like potassium dihydrogen orthophosphate (KDP), ammonium dihydrogen orthophosphate (ADP), magnesium sulphate heptahydrate (MSH) and zinc tris(thiourea) sulphate (ZTS). The presence of impurity molecules, even at lower concentrations in the parent solute, may have considerable effect on the growth kinetics and other properties.

LAA crystals were grown by the slow evaporation method and investigated the effect of $\mathrm{NaCl}, \mathrm{KCl}$, glycine and urea (added separately) as impurities and results obtained have been reported [3]. $\mathrm{Cu}^{2+}$ and $\mathrm{Mg}^{2+}$ doped LAA crystals show positive photoconductivity and the hardness of the crystal decreases with increasing load both for pure and doped samples [4]. $\mathrm{Cu}^{2+}$ and $\mathrm{Mg}^{2+}$ doped LAA were grown by the slow evaporation technique and thermally stabilized crystals were obtained [5]. Li doped LAA crystals were grown by the slow evaporation method and was found to have good optical transparency [6].

L-Arginine is an amino acid which forms a number of complexes on reaction with different acids and has attractive NLO properties [7]. LAA crystallizes in the monoclinic crystal system with space group $\mathrm{P} 2_{1}$. In the present investigation, a systematic study has been carried out on the growth and characterization of pure and hydrochloric acid doped (at different concentrations) crystals. Herewith we report the results obtained in the present study.

\subsection{Crystal growth}

\section{Experimental}

Equimolar quantity of AR grade L-arginine and acetic acid were taken and dissolved to super saturation in doubly deionised water to prepare the aqueous solution of LAA. The reaction that takes place between L-Arginine and acetic acid in aqueous medium is as follows:

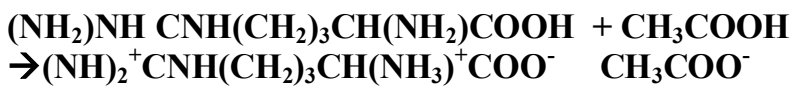


The growth of acid doped crystal is achieved by using the same procedure and then adding $\mathrm{HCl}$ acid (four different concentrations were considered: $0.08,0.1,0.3$ and $0.4 \mathrm{~mol} \%$ ) to the LAA solution. The pure and doped crystals were yielded within a period of 15-20 days. The $\mathrm{pH}$ of doped solution at each concentration was found to be between $5 \& 6$. The grown crystals are represented as LAA, LAAH1, LAAH2, LAAH3, and LAAH4 respectively for pure LAA and $0.08,0.1,0.3$, and $0.4 \mathrm{~mol} \% \mathrm{HCl}$ added LAA.

\subsection{Characterizations}

The densities of the crystals were measured by the floatation method with a mixture of carbon tetra chloride (density-1.592 g/cc) and hexane (density-0.652 g/cc) taken as high and low density liquids respectively. CHNS analysis was done using an Elementar Vario EL III, Germany to estimate carbon, hydrogen and nitrogen contents present in the grown crystals. The grown crystals were subjected to single crystal X- Ray diffraction (SXRD) analysis using an ENRAF - NONIUS CAD4 single crystal X-Ray diffractometer and the lattice parameters were determined. X-Ray powder diffraction (PXRD) analysis was also carried out to understand the crystallinity by using an XPERT-PRO PANalytical diffractometer with monochromated $\mathrm{CuK}_{\alpha}$ radiation. The reflections were indexed, following the procedures of Lipson and Steeple [8]. Energy dispersive X-ray (EDX) spectroscopic analysis was carried out to estimate the chlorine content in the doped crystals by using a scanning electron microscope equipped with EDX.

The Fourier transform infrared (FTIR) spectra were recorded using a MAGNA 550 model spectrometer in the wavenumber range $400-4000 \mathrm{~cm}^{-1}$. In order to find the transparent nature of the crystals, UV-Vis spectra were recorded in the wavelength range 200-800 nm using a Vario Cary 500 scan spectrophotometer. SHG measurements were made for all the grown crystals using a1064 nm Quantam ray series Molectron powermeter, USA. Thermal studies were carried out using an SDT Q600 V8.3 Build 101 analyzer for a temperature range $40-800{ }^{\circ} \mathrm{C}$ in the air atmosphere to understand the thermal stability of the grown crystals. Mechanical strength of the grown crystals were understood by measuring the microhardness with the help of a Leitz-Weitzler microhardness tester.

The capacitance $\left(\mathrm{C}_{\text {crys }}\right)$ and dielectric loss factor $(\tan \delta)$ measurements were carried out to an accuracy of $\pm 1 \%$ for all the crystals grown by having the large area faces touching the electrodes by the parallel plate capacitor method [9-12] using an LCR meter (Agilant 4284A) at various temperatures ranging from $40-140{ }^{\circ} \mathrm{C}$ with three different frequencies, viz. 1,10 , and $100 \mathrm{kHz}$. The temperature was controlled to an accuracy of \pm 1 ${ }^{\circ} \mathrm{C}$. The observations were made while cooling the sample. The dimensions of the crystals were measured using a traveling microscope. Air capacitance $\left(\mathrm{C}_{\mathrm{air}}\right)$ was also measured. Since the variation of air capacitance with frequency was found to be negligible, air capacitance measured only at the lower temperature was considered. The crystals were shaped and polished and the opposite faces were coated with graphite to form a good conductive surface layer (ohmic contact). The sample was mounted between the silver electrodes and annealed at $140{ }^{\circ} \mathrm{C}$ for about $30 \mathrm{~min}$ to homogenize the sample before taking the readings.

As the crystal area was smaller than the plate area of the cell, the real part of the dielectric constant $\left(\epsilon^{\prime}\right.$ $=\varepsilon_{\mathrm{r}}$ ) of the crystal was calculated using Mahadevan's formula [13-16]

$\varepsilon^{\prime}=\varepsilon_{\mathrm{r}}=($ Aair/Acrys $)(($ Ccrys - Cair $)(1$ - Acrys/Aair $)) /$ Cair $)$,

where $\mathrm{C}_{\text {crys }}$ is the capacitance with crystal (including air), $\mathrm{C}_{\text {air }}$ is the capacitance of air, $\mathrm{A}_{\text {crys }}$ is the area of the electrode.

The AC electrical conductivity, $\sigma_{\mathrm{AC}}$ was calculated using the relation

$\sigma_{\mathrm{AC}}=\varepsilon_{0} \varepsilon_{\mathrm{r}} \tan \delta$,

where $\varepsilon_{0}$ is the permittivity of free space $\left(8.85 \times 10^{-12} \mathrm{C}^{2} \mathrm{~N}^{-1} \mathrm{~m}^{-2}\right), \omega$ is the angular frequency $(\omega=2 \pi \mathrm{f} ; \mathrm{f}=1,10$ $\& 100 \mathrm{kHz}$ in the present study) and tan $\delta$ is the dielectric loss factor.

\subsection{Densities, lattice parameters and chemical composition}

\section{Results And Discussion}

The crystals grown in the present study, both pure and doped LAA, are found to be colorless and transparent .The photographs of the sample crystals grown are shown in Figure 1. It is found that as dopant concentration increases the transparency of the crystal increases.

The weight percentages of carbon, hydrogen and nitrogen observed to be present in both pure and doped LAA are shown in Table.1. The $\mathrm{C}$ and $\mathrm{N}$ concentrations observed do not change significantly due to doping with $\mathrm{HCl}$. However, the observed change in $\mathrm{H}$ concentration shows the incorporation of the dopant into the LAA crystal matrix.

The measured densities and lattice parameters obtained through SXRD analysis for all the grown crystals are given in Table 2. The change in lattice volume observed with $\mathrm{HCl}$ addition is not significant enough to derive any conclusion. However, it is understood that there is no lattice distortion caused due to $\mathrm{HCl}$ addition. The lattice parameters observed for the pure LAA in the present study compare well with that reported in the 


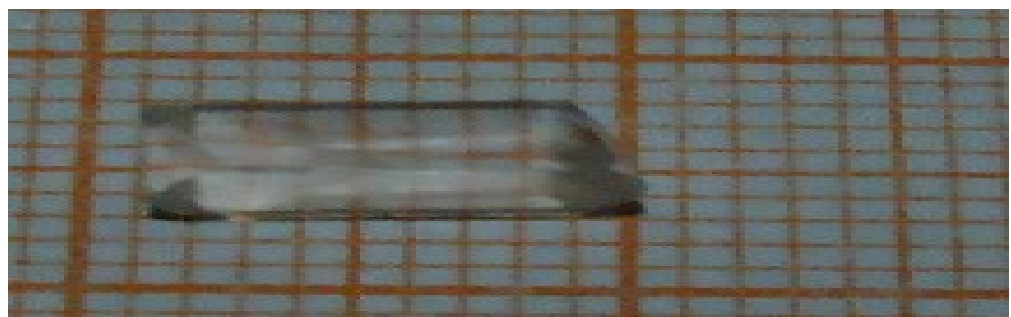

(a)

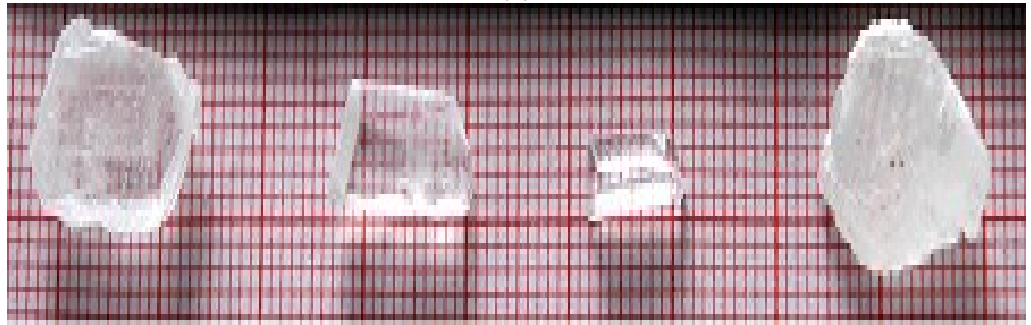

(b)

Figure 1: Photographs of the sample crystals grown [(a) LAA (b) From right: LAAH1, LAAH2, LAAH3, LAAH4]

literature. The density is found to increase with the increase in $\mathrm{HCl}$ concentration in the solution used for the growth of single crystal. This indicates clearly that the dopant $(\mathrm{HCl})$ has gone into the LAA crystal matrix nearly in proportion with the concentration of $\mathrm{HCl}$ in the solution.

PXRD patterns obtained in the $2 \theta$ range $10-70^{\circ}$ are shown in Figure 2. The PXRD pattern for pure LAA obtained in the present study is essentially identical with the already published one which confirms the material of the grown crystal [3]. The PXRD patterns obtained for the impurity added LAA

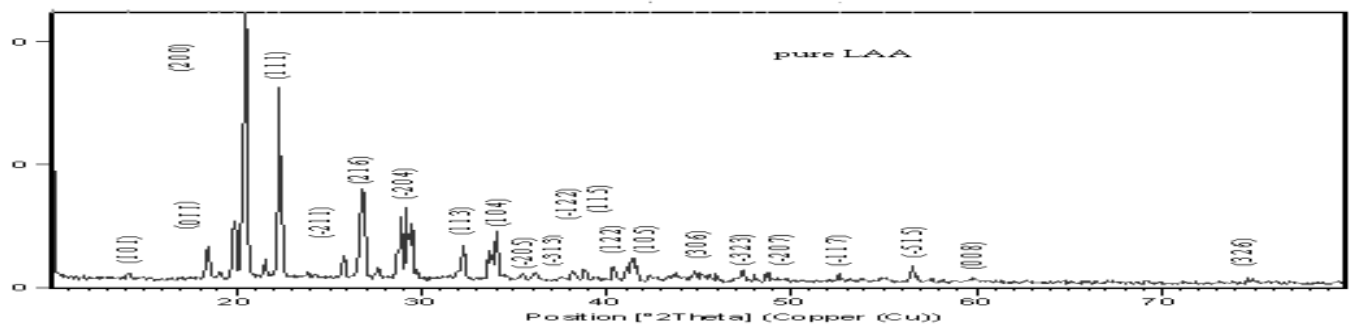

(a)

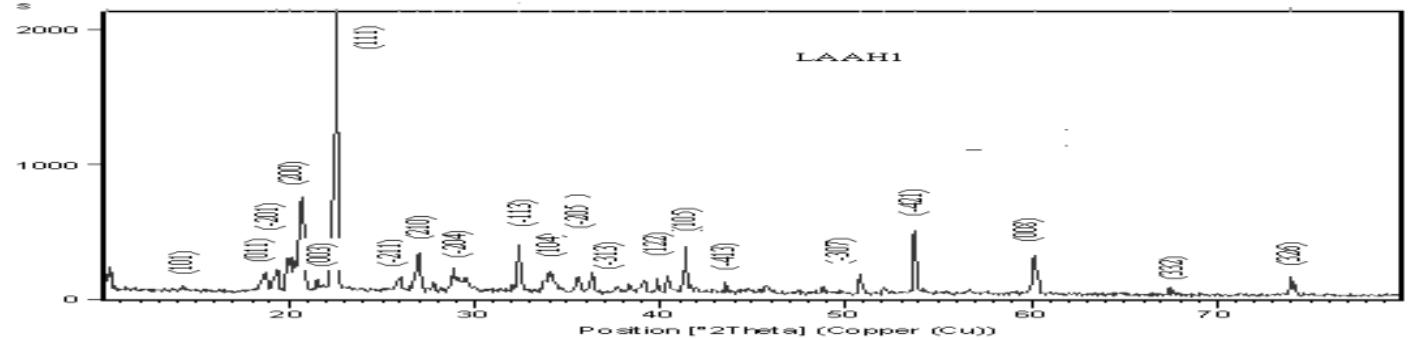

(b)

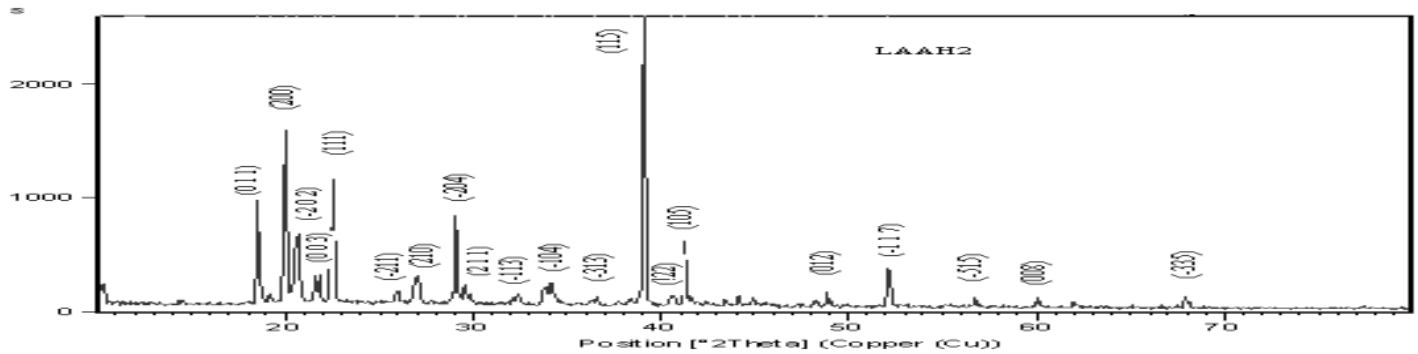

(c) 


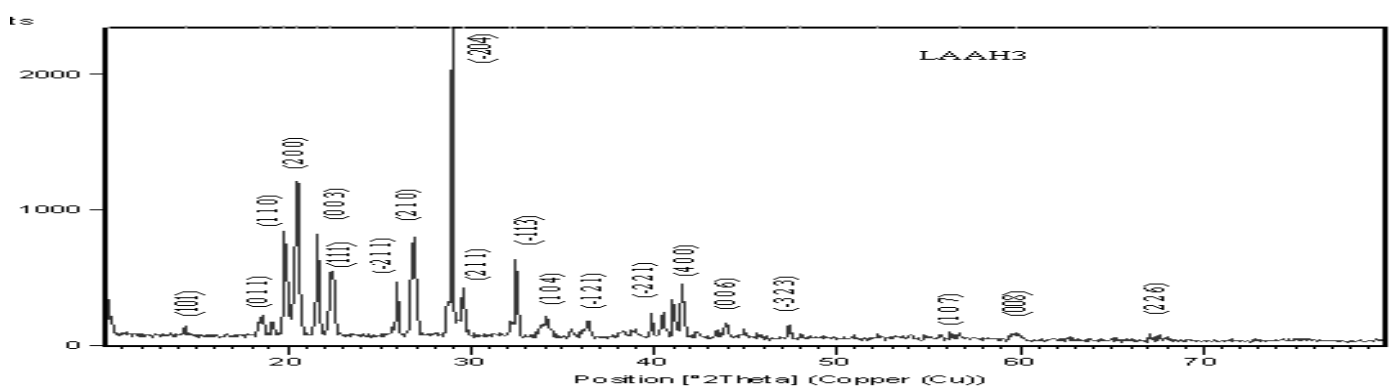

(d)

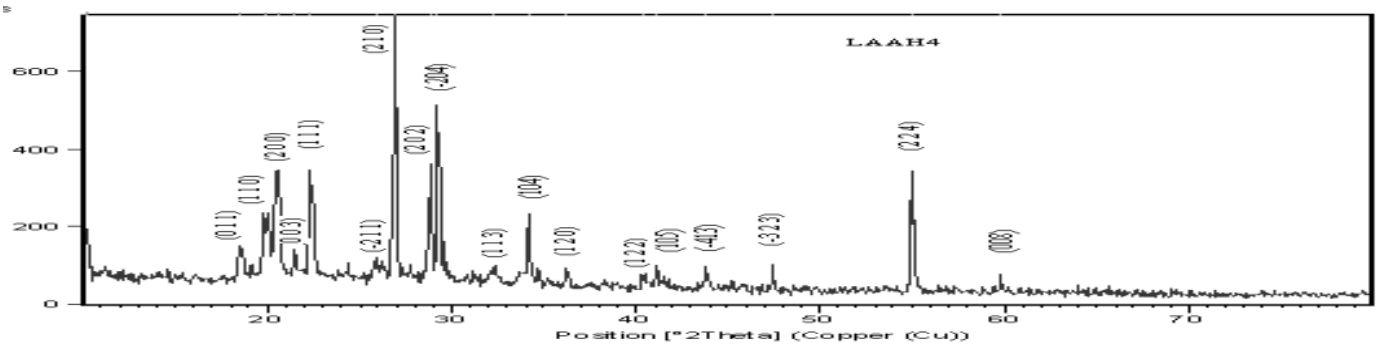

(e)

Figure 2: The observed PXRD patterns

crystals are almost identical (but with some intensity differences) with that for the pure LAA which again indicates that there is no lattice distortion caused due to doping. The sharp and intense peaks observed indicate the higher crystallinity of the crystals grown.

Table 1: Results of CHNS analysis

\begin{tabular}{|l|l|l|l|}
\hline \multirow{2}{*}{ Crystal } & \multicolumn{4}{|l|}{ Composition (\%) } \\
\cline { 2 - 4 } & $\mathrm{C}$ & $\mathrm{H}$ & $\mathrm{N}$ \\
\hline LAA & 40.98 & 12.82 & 24.52 \\
\hline LAAH1 & 40.84 & 13.16 & 24.50 \\
\hline LAAH2 & 40.98 & 12.59 & 24.40 \\
\hline LAAH3 & 40.95 & 12.08 & 24.34 \\
\hline LAAH4 & 40.85 & 10.53 & 24.30 \\
\hline
\end{tabular}

Table 2 : The observed lattice parameters and densities [Values given in parentheses are from literature]

\begin{tabular}{|l|l|l|l|l|l|l|}
\hline Crystal & $\mathrm{a}(\AA)$ & $\mathrm{b}(\AA)$ & $\mathrm{c}(\AA)$ & $\beta^{0}$ & Volume $\left(\AA^{3}\right)$ & Density $(\mathrm{g} / \mathrm{cc})$ \\
\hline Pure LAA & 9.189 & 5.166 & 13.050 & 109.62 & 584 & 1.322 \\
& $(9.199)$ & $(5.182)$ & $(13.175)$ & $(11.1)$ & $(586.2)$ & \\
\hline LAAH1 & 9.200 & 5.181 & 13.080 & 109.56 & 587.5 & 1.339 \\
\hline LAAH2 & 9.240 & 5.200 & 13.130 & 109.38 & 595.0 & 1.354 \\
\hline LAAH3 & 9.206 & 5.178 & 13.070 & 109.55 & 587.3 & 1.367 \\
\hline LAAH4 & 9.195 & 5.155 & 13.052 & 109.60 & 587.8 & 1.496 \\
\hline
\end{tabular}

EDX spectral analysis was done to the LAAH1, LAAH2, LAAH3 and LAAH4 crystals to confirm the presence of chlorine in these crystals. The estimated chlorine contents of the doped crystals are compared with the corresponding chlorine contents of the solution used for the growth of single crystals in Table 3 . EDX analysis indicates the presence of chlorine atoms in the doped crystals. The chlorine concentration in crystal is found to be less but in proportion to that considered in the solution used for the growth of single crystals.

Table 3: The chlorine contents

\begin{tabular}{|l|l|l|}
\hline \multirow{2}{*}{ Crystal } & Chlorine content (mol\%) \\
\cline { 2 - 3 } & In solution & In crystal \\
\hline LAAH1 & 0.08 & 0.03 \\
\hline LAAH2 & 0.10 & 0.04 \\
\hline LAAH3 & 0.30 & 0.14 \\
\hline LAAH4 & 0.40 & 0.16 \\
\hline
\end{tabular}


The FTIR spectra recorded in the present study are shown in Figure 3. The spectra are found to be complex as a result of various functional groups present in the pure and doped LAA crystals. The vibrational band assignments are given in Table 4. The FTIR spectra of doped crystals are almost similar to that of pure LAA. However, the spectra for doped crystals reveal a remarkable change in absorption level due to stretching modes, in between the band ranging from 1600 to $1200 \mathrm{~cm}^{-1}$, when the molar concentration of the $\mathrm{HCl}$ is increased. This indicates the inclusion of $\mathrm{HCl}$ molecules into the LAA crystal matrix

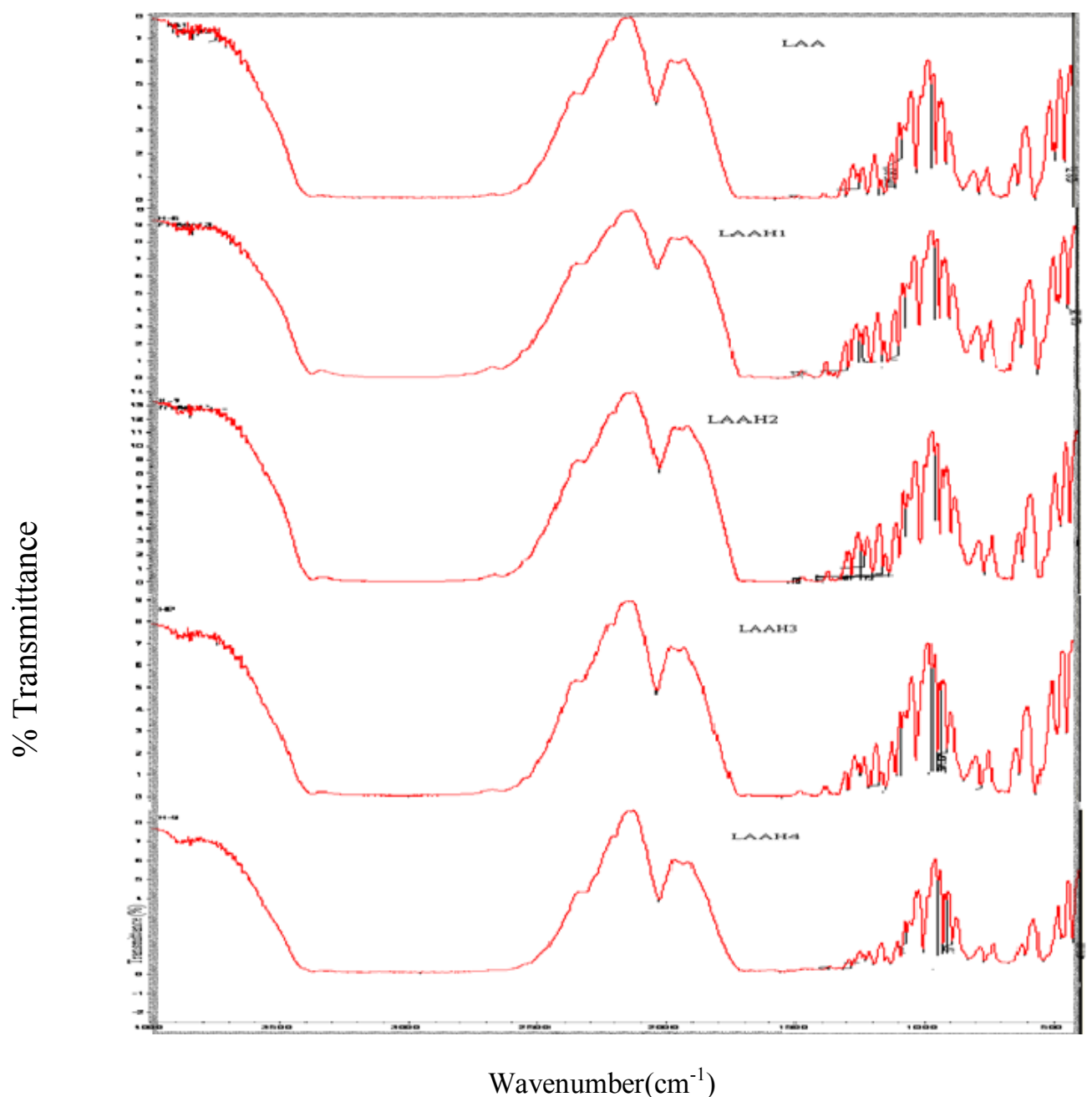

Figure 3: The observed FTIR spectra

Table 4: The FTIR (vibrational) band assignments

\begin{tabular}{|l|l|l|l|l|l|l|}
\hline $\begin{array}{l}\text { LAA } \\
\text { Reported [6] } \\
\mathrm{cm}-1\end{array}$ & $\begin{array}{l}\text { LAA1 } \\
\text { (present } \\
\text { work }) \mathrm{cm}-1\end{array}$ & $\begin{array}{l}\text { LAAH1 } \\
\mathrm{cm}-1\end{array}$ & $\begin{array}{l}\text { LAAH2 } \\
\mathrm{cm}-1\end{array}$ & $\begin{array}{l}\text { LAAH3 } \\
\mathrm{cm}-1\end{array}$ & $\begin{array}{l}\text { LAAH4 } \\
\mathrm{cm}-1\end{array}$ & Assignment \\
\hline $3750-2300$ & 3898.12 & 3898.15 & 3897.92 & 3897.98 & 3879.29 & $\begin{array}{l}\text { NH and CH stretching } \\
\text { vibrations }\end{array}$ \\
\hline & 3178.60 & 3041.05 & 3051.64 & 2997.73 & 2956.28 & $\begin{array}{l}\text { NH Stretching of NH2 } \\
\text { vibration }\end{array}$ \\
\hline 1532 & 1557.39 & 1558.78 & 1519.99 & 1542.24 & 1558.14 & $\begin{array}{l}\text { Asymmetric stretching } \\
\text { modes of COO- }\end{array}$ \\
\hline & & 1.412 .44 & & & & CH3 symmetric deformation \\
\hline & & 1322.92 & 1323.06 & 1323.17 & & Stretching vibration of CO \\
\hline & 1278.09 & 1278.13 & 1278.21 & 1278.06 & 1278.07 & CH3 wagging \\
\hline & 1229.10 & 1229.04 & 122912 & 1229.66 & 1229.01 & CH2 twisting \\
\hline 1228 & 1197.02 & 1197.05 & 1197.17 & 1196.94 & 1196.97 & -COO vibrations \\
\hline 1093 & 1089.74 & 1089.69 & 1089.79 & 1089.69 & 1089.60 & C-CN stretching vibrations \\
\hline 928 & 928.93 & 928.94 & 928.88 & 928.98 & 928.89 & C-CH bending \\
\hline & & & & 915.03 & 914.82 & $\begin{array}{l}\text { Overtone of torsional } \\
\text { oscillation of NH3+ }\end{array}$ \\
\hline 670 & 675.87 & 653.15 & 653.42 & 653.87 & 667.85 & NH out of plane bending \\
\hline 543 & 542 & 544.75 & 544.22 & 544.56 & 541.72 & $\begin{array}{l}\text { Torsional NH oscillation of } \\
\text { NH }{ }^{+} \text {group }\end{array}$ \\
\hline
\end{tabular}




\subsection{Thermal, optical and mechanical properties}

The TG, DTA and DSC patterns observed in the present study for LAA and LAAH4 crystals are shown in Figure 4. From the curves it is observed that the decomposition of LAA starts at $204^{\circ} \mathrm{C}$. This is supported by the DTA analysis where the endothermic reaction is observed at $202^{\circ} \mathrm{C}$. It can be seen from the thermal analysis that LAA subjected to continuous heating does not remain stable for a long temperature change. However, it is decomposed at a temperature of $582{ }^{\circ} \mathrm{C}$ and forms a residue. Above $633{ }^{\circ} \mathrm{C}$ the product is stable without any prominent weight loss. LAAH4 starts decomposing at $204{ }^{\circ} \mathrm{C}$. Other decomposition temperature points are 301, 394,482 and $567{ }^{\circ} \mathrm{C}$. Above $567{ }^{\circ} \mathrm{C}$ there is no prominent weight loss.

The DSC analysis for LAA and LAAH4 shows no endothermic or exothermic transitions below 200 ${ }^{0} \mathrm{C}$, the materials are proved to be stable in this region. The resistivity of the materials against thermal crack is evident as the DSC trace is smooth up to nearly $200{ }^{\circ} \mathrm{C}$. It is the property observed for compounds where the lattice force is more predominating than the covalent bonding forces in molecules. It is also observed that the electrostatic force that originated as a result of perfect proton transfer between acetic acid and L-arginine becomes dominating to provide resistance to melting before decomposition.

The range and percentage of optical transmission of pure and doped LAA crystals have been studied by using the UV - Vis absorption spectra of the grown crystals recorded in the wavelength range $200-800 \mathrm{~nm}$. The observed spectra are shown in Figure 5.
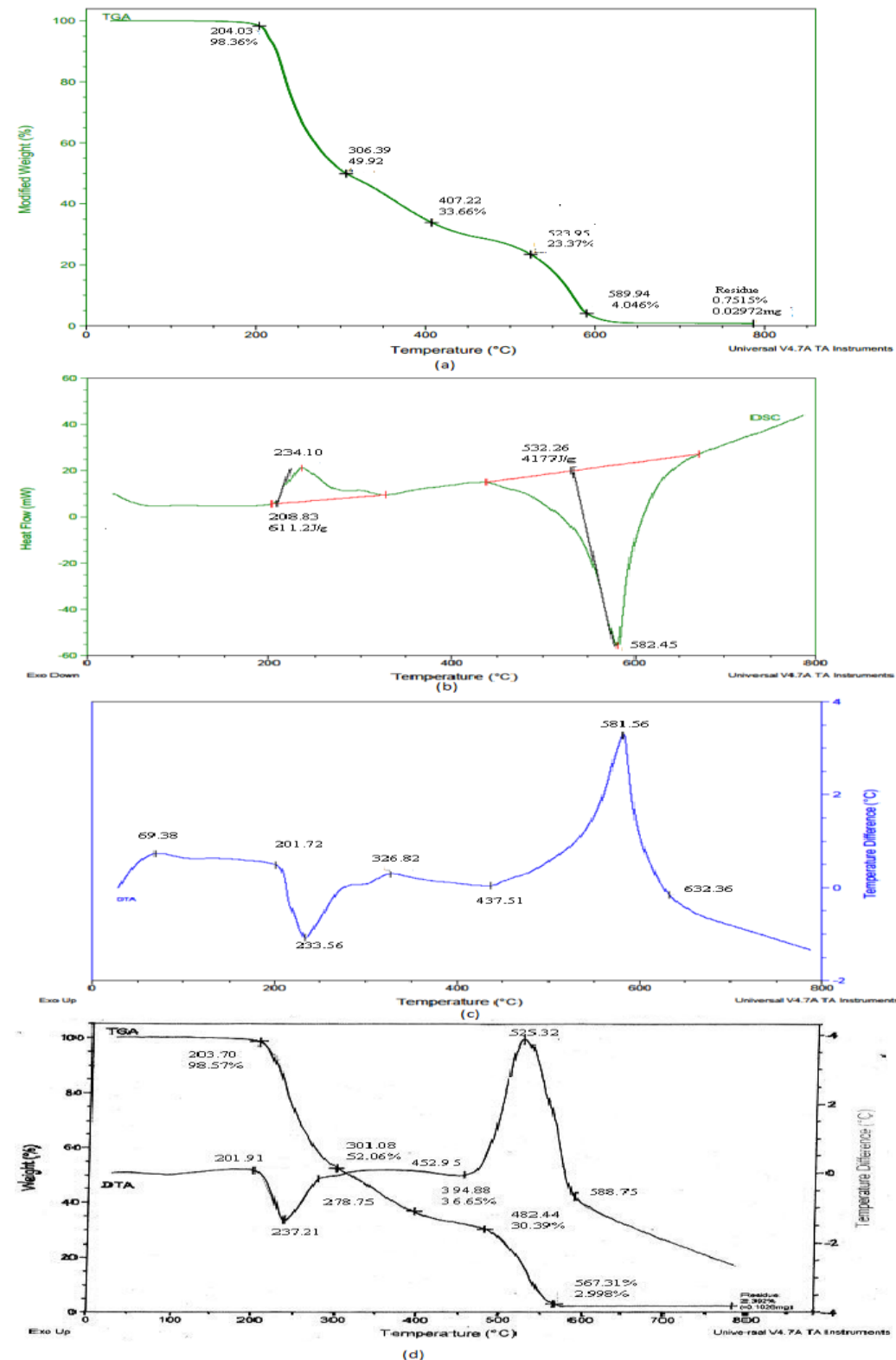


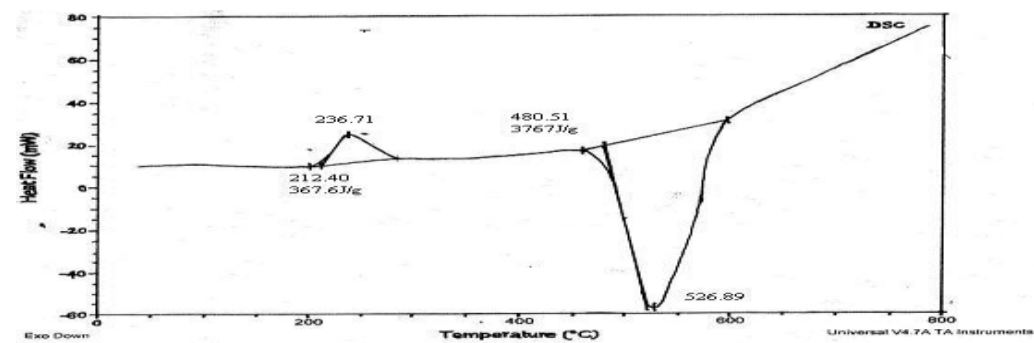

(e)

Figure 4: The observed thermograms of LAA and LAAF4 crystals [(a), (b) and (c) : TG, DSC and DTA curves of LAA crystal ; (d) and (e) : TG/DTA and DSC curves of LAAF4 crystal]

The cutoff wavelengths (absorption edges) for both pure and doped LAA crystals are given in Table 5 . It is observed that the lower cut off wavelength is around $235 \mathrm{~nm}$ and the transparency conveniently extends to $800 \mathrm{~nm}$. From the high energy edge of transmission the forbidden energy gap $\mathrm{E}_{\mathrm{g}}$ determined for the pure and doped LAA crystals are found to be more than $5 \mathrm{eV}$.

The SHG capability of the grown crystals were confirmed by the Kurtz and Perry method. Nd:YAG laser of $1064 \mathrm{~nm}$ wavelength was used to irradiate the samples. Second harmonic signal was captured by the oscilloscope through the photomultiplier tube. Urea crystal was used as a reference material in the SHG efficiency measurement. The samples were tested using an $\mathrm{i} / \mathrm{p}$ pulse $0.68 \mathrm{~J}$. The second harmonic signal obtained for the grown crystals, with reference to urea, are given in Table 5. The SHG efficiencies of all the five crystals grown in the present study are found to be comparable to that of urea.

Table 5: The optical absorption edges, SHG efficiencies and work hardening coefficients observed in the present study

\begin{tabular}{|l|l|l|l|}
\hline Crystal & Absorption edge $(\mathrm{nm})$ & SHG efficiency (in urea unit) & Work hardening coefficient (n) \\
\hline LAA & 237 & 0.81 & 3.361 \\
\hline LAAH1 & 235 & 0.69 & 4.178 \\
\hline LAAH2 & 230 & 0.78 & 3.893 \\
\hline LAAH3 & 233 & 0.89 & 3.819 \\
\hline LAAH4 & 232 & 0.84 & 3.273 \\
\hline
\end{tabular}

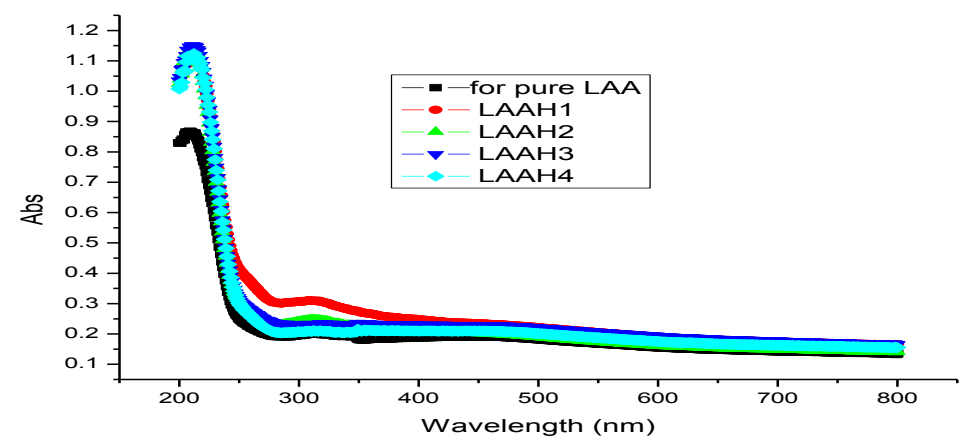

Figure 5: The observed UV-Vis absorption spectra

Hardness is defined as the resistance offered by a material to external mechanical action endeavoring to scratch, indent, or any other way affecting its structure. Microhardness measurements of the grown crystals were done using Vicker's Hardness Indenter using a Leitz Weitzler Hardness Tester. The indentation time was fixed as $10 \mathrm{~s}$. Vicker's Hardness Number $\left(\mathrm{H}_{\mathrm{V}}\right)$ was calculated using the relation

$$
\mathrm{H}_{\mathrm{V}}=1.8554 \mathrm{P} / \mathrm{d}^{2} \mathrm{~kg} / \mathrm{mm}^{2} \text {. }
$$

Here $\mathrm{P}$ is the load applied and $\mathrm{d}$ is the diagonal length of the indented impressions. Plots between the load $\mathrm{P}$ and hardness number $\mathrm{H}_{\mathrm{V}}$ are shown in Figure 6 which indicate that the hardness number increases with increasing load. Hardness number is found to decrease due to doping but not systematically with the concentration of the dopant in the crystal. 


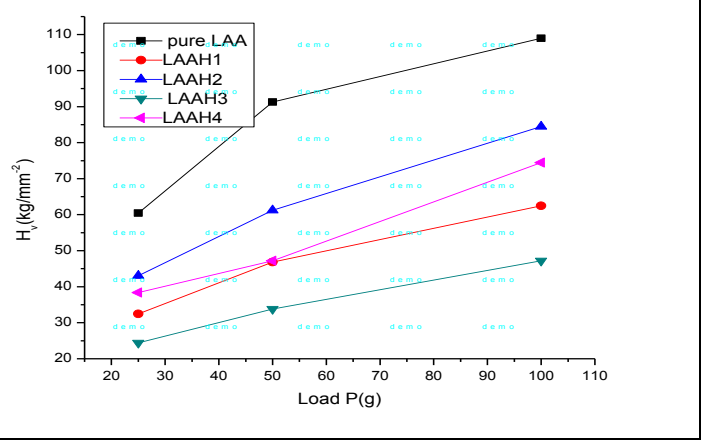

Figure 6: Variation of Vicker's hardness number with load P for pure and doped LAA crystals

Log d vs Log P plots made (not shown here) were found to be nearly linear. The work hardening coefficients (n) were estimated from the slopes of the curves using the least square fit method. The ' $n$ ' values are found to be greater than 2, hence the materials are cosidered to be soft ones.

According to Onitsch, if $n>2$ the materials are said to be soft ones. He also found that microhardness increases with increasing load when $n>2$ and decreases with increasing load when $n<2$ [17]. The increase in $H_{V}$ for increasing load observed in the present study is in good agreement with the theoretical prediction.

The optical and mechanical parameters like optical absorption edge wavelength, SHG efficiency and work hardening coefficient do not vary systematically with the impurity concentration. However, it is found that $\mathrm{HCl}$ doping tunes significantly the optical and mechanical properties of the LAA crystal.

\subsection{Electrical properties}

The study of dielectric constant of a material gives an outline about the nature of atoms, ions and their bonding in the material. The capacitances and dielectric loss factors were measured along the major growth direction for all the crystals grown in the present study. From these measured values, the dielectric constant and AC electrical conductivity were determined. The $\varepsilon_{\mathrm{r}}$, tan $\delta$ and $\sigma_{\mathrm{AC}}$ values obtained in the present study are shown in Figures 7, 8 and 9 respectively.

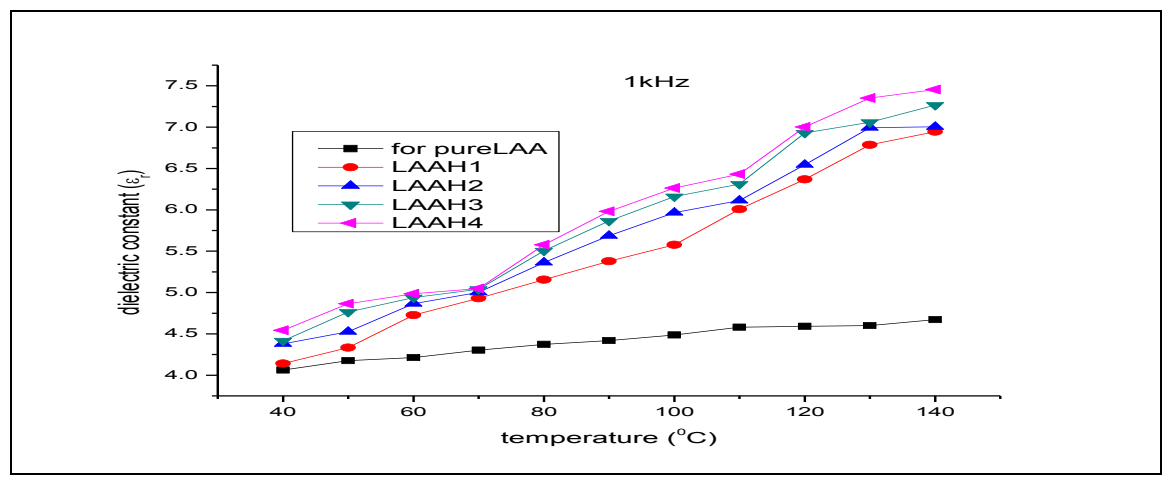

(a)

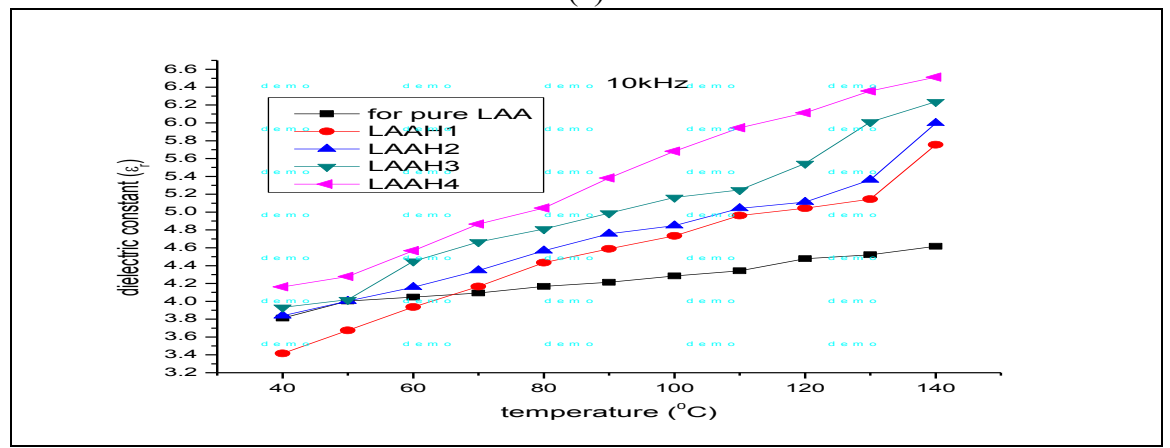

(b) 


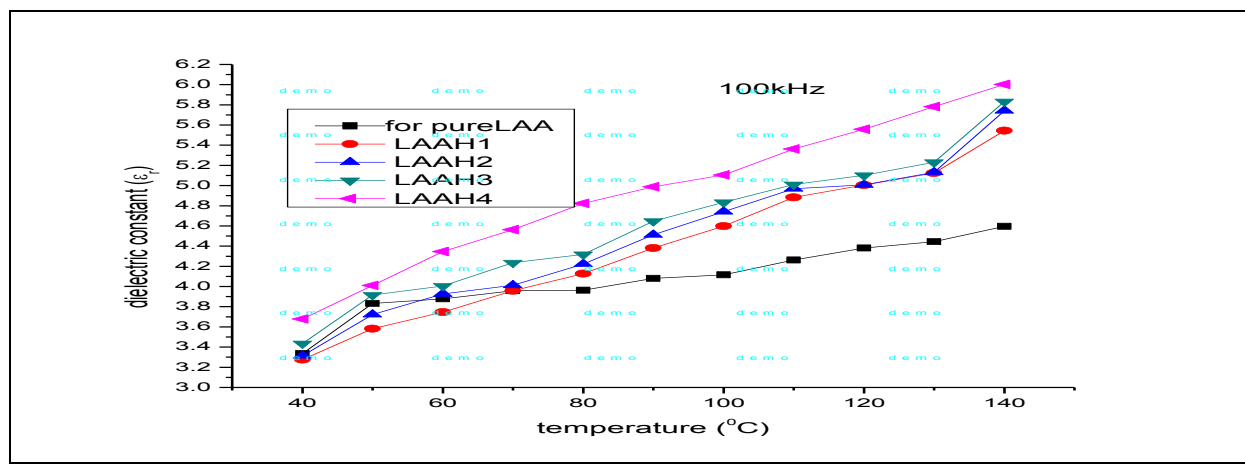

(c)

Figure 7: The observed dielectric constants

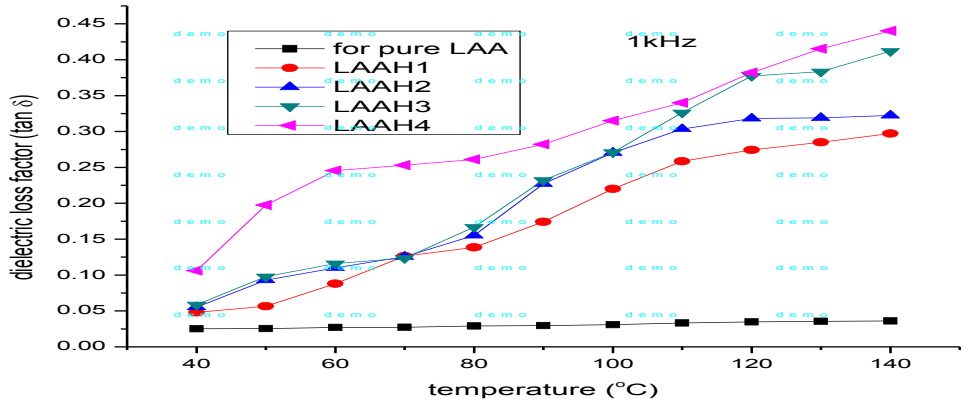

(a)

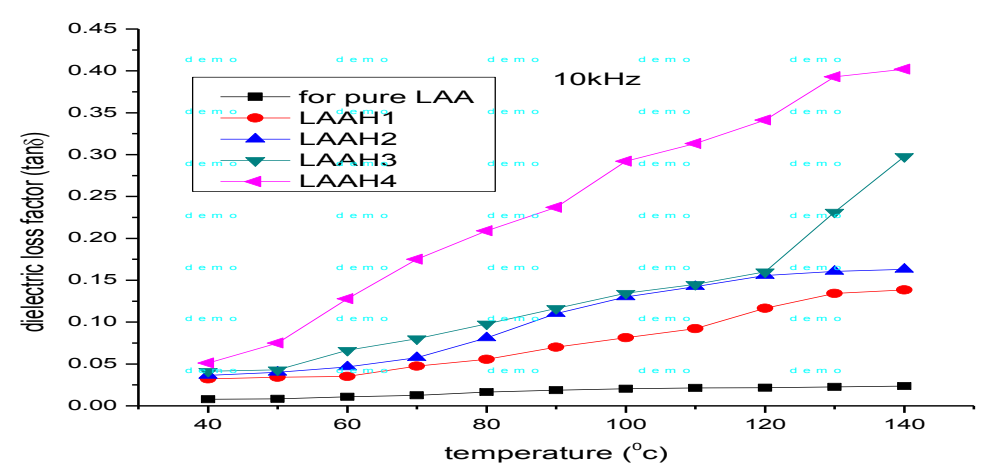

(b)

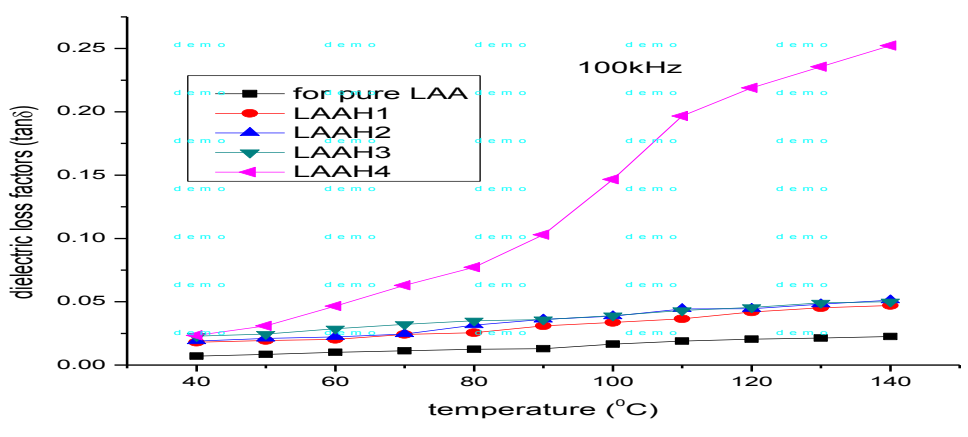

(c)

Figure 8: The observed dielectric loss factors 


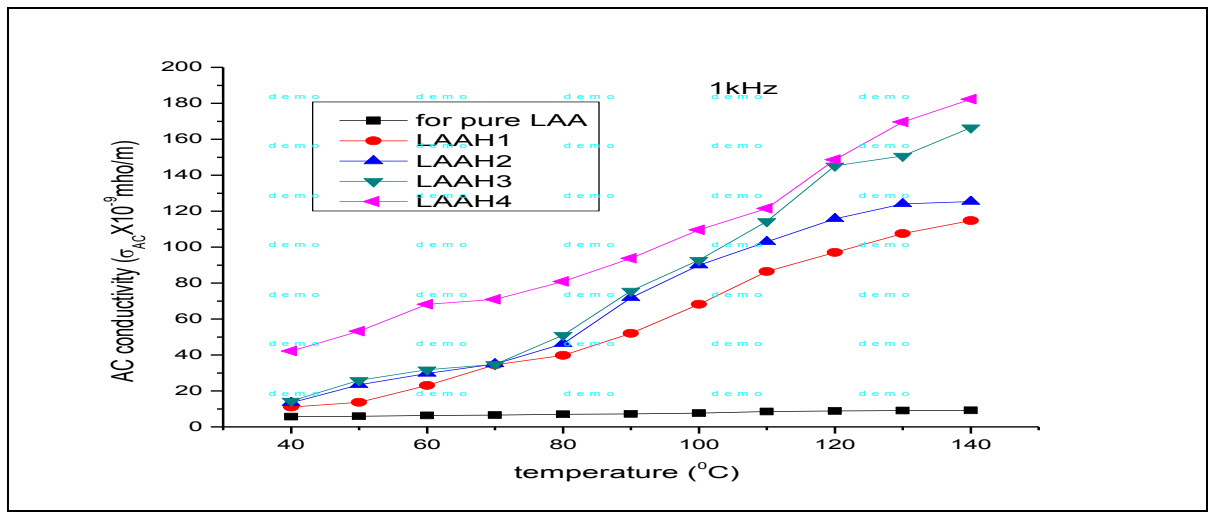

(a)

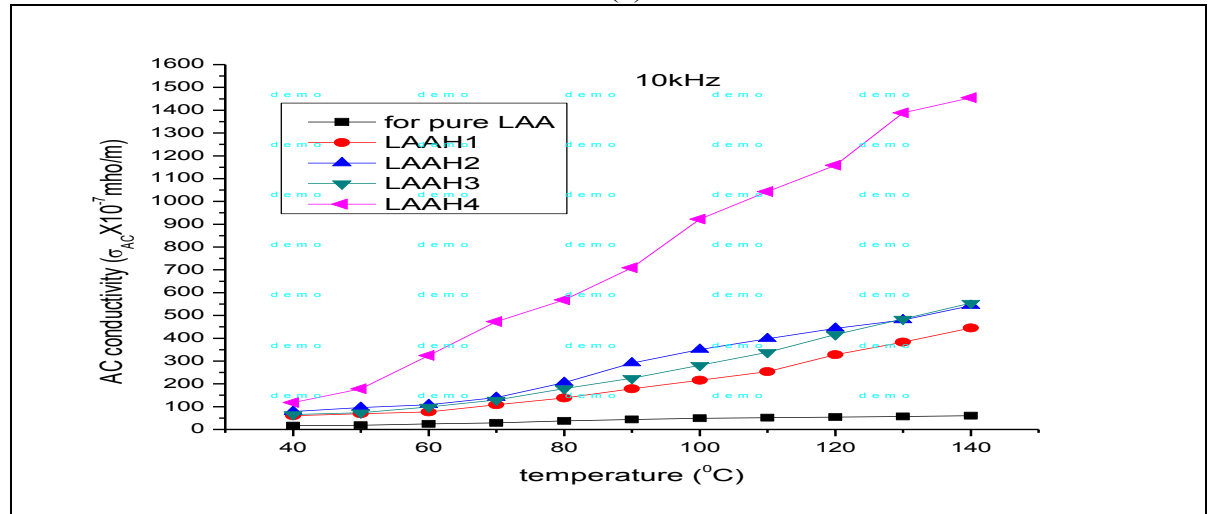

(b)

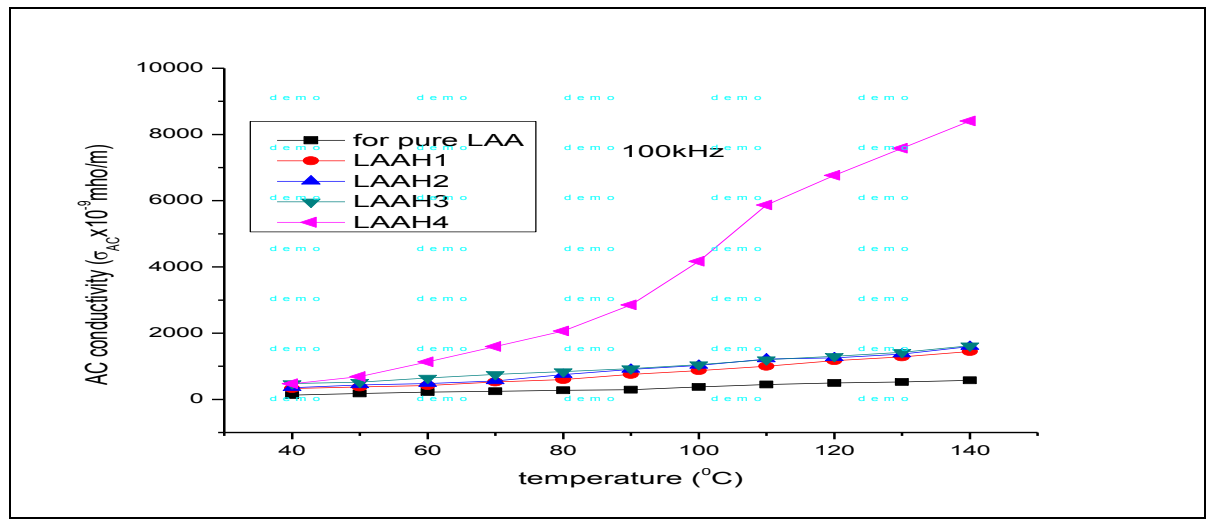

(c)

Figure 9: The observed AC electrical conductivities

It has been found that all the three dielectric parameters increase with the increase in temperature. Also, the $\varepsilon_{\mathrm{r}}$ and $\tan \delta$ values are found to decrease whereas the $\sigma_{\mathrm{AC}}$ value is found to increase with the increase in frequency. This is a normal dielectric behavior [18]. Moreover, all the three dielectric parameters increase due to doping and approximately increase with the increase in impurity concentration.

The $\mathrm{AC}$ electrical conductivity $\left(\sigma_{\mathrm{AC}}\right)$ values observed at various temperatures for all the frequencies were fitted into the Arrhenius type relation

$\sigma_{\mathrm{AC}}=\sigma_{0 \mathrm{AC}}[\exp (-\mathrm{E} / \mathrm{kT})]$,

where $\mathrm{E}_{\mathrm{AC}}$ is the activation energy, $\mathrm{k}$ is the Boltzmann's constant, $\mathrm{T}$ is the absolute temperature and $\sigma_{0 \mathrm{AC}}$ is the constant that depends on the material of the crystals. The AC activation energy was estimated by using the least square analysis procedure after plotting the $\sigma_{\mathrm{AC}}$ values against 1/T [19 ]. The estimated AC activation energies $\left(\mathrm{E}_{\mathrm{AC}}\right)$ are given in Table 6 . The low $\mathrm{E}_{\mathrm{AC}}$ values observed in the temperature range considered indicate the presence of oxygen vacancies. The variation of $\mathrm{E}_{\mathrm{AC}}$ is found to be not systematic with both frequency and impurity concentration. 
Table 6: The estimated AC activation energies

\begin{tabular}{|l|l|l|l|}
\hline \multirow{2}{*}{ Crystal } & \multicolumn{3}{|l|}{$\begin{array}{l}\text { AC activation energy } \mathrm{E}_{\mathrm{AC}}(\mathrm{eV}) \\
\text { for the frequency }\end{array}$} \\
\cline { 2 - 4 } & $1 \mathrm{kHz}$ & $10 \mathrm{kHz}$ & $100 \mathrm{kHz}$ \\
\hline LAA & 0.057 & 0.153 & 0.157 \\
LAAH1 & 0.274 & 0.227 & 0.173 \\
LAAH2 & 0.255 & 0.234 & 0.173 \\
LAAH3 & 0.274 & 0.253 & 0.136 \\
LAAH4 & 0.159 & 0.276 & 0.335 \\
\hline
\end{tabular}

Studies on the dependences of temperature and frequency on dielectric constant, dielectric loss factor and $\mathrm{AC}$ electrical conductivity unveil useful information about defect behavior, structural changes and transport phenomenon. The dielectric properties can be correlated with the electro-optic property of crystals [20].

The higher values of dielectric constant and dielectric loss observed at lower frequencies can be attributed to space charge polarization owing to the charged lattice defects [21]. The dielectric constants observed for the grown crystals are considerably low which is important for extending the material applications towards photonic, electro-optic and NLO devices. Also, the low dielectric losses observed indicate that the crystals grown in the present study are of good quality.

The electrical conduction mechanism for the crystals grown in the present study can be established as due to protonic transport as in the case of ADP, KDP and MSH [15, 22]. Also, the temperature dependences of dielectric constant and $\mathrm{AC}$ electrical conductivity can be explained as due to the temperature dependences of ionic polarizability and protonic transport respectively.

\section{Conclusion}

Pure and hydrochloric acid doped LAA crystals (a total of 5 crystals) have been grown successfully by the slow evaporation method and characterized chemically, structurally, optically, thermally, mechanically and electrically. SXRD, PXRD, CHNS elemental, EDX spectral and FTIR spectral analyses and density measurement indicate that all the crystals grown belong to monoclinic crystal system with good crystallinity and the material of the grown crystals is basically L-arginine acetate. Also, $\mathrm{HCl}$ molecules are found to be incorporated into the LAA crystal matrix without distorting the crystal structure. Thermal and mechanical measurements indicate a good thermal stability up to $204{ }^{\circ} \mathrm{C}$ and mechanically soft nature for all the crystals grown. UV-Vis absorption and SHG efficiency measurements indicate a wide transparency range and good NLO property comparable to that of urea crystal. Dielectric measurements indicate a normal dielectric behavior for all the crystals grown and an increase of dielectric parameters like dielectric constant, dielectric loss factor and $\mathrm{AC}$ electrical conductivity due to $\mathrm{HCl}$ addition as an impurity to LAA. The present study indicates that $\mathrm{HCl}$ doping tunes significantly the optical, mechanical and dielectric properties of the LAA crystal and the crystals grown are expected to be useful in photonics and opto-electronics industries.

\section{References}

[1]. Tanusri Pal and Tanusree Kar (2005) Mater. Chem. Phys. 91, 343-347.

[2]. M.Meena and C.K.Mahadevan (2008) Mater. Lett. 62, 3742-3744

[3]. M.Meena and C.K.Mahadevan (2010) Arch. Appl. Sci. Res.2(6), 185-199.

[4]. M. Gulam Mohamed, M. Vimalan, J.G.M. Jesudurai, J. Madhavan,and P. Sagayaraj(2007) Cryst. Res. Technol. 42, 948-954.

[5]. N. Kanagathara, G. Anbalagan, N.G. Renganathan (2011) Int. J. Chem.Res. 1 (3),11-15.

[6]. V. Natarajan, M. Arivanandhan,K.Sankaranarayanan, P. Ramasamy (2009) J. Sci.Technol. 3(8) 897-899.

[7]. X.J. Liu, Z.Y.Wang, X.Q. Wang, G,H. Zhang,S.X. Xu, A.D. Duan, S.J.Zhang, Z.H. Sun, and D. Xu (2008) Cryst. Growth \& Design 8(7),2270-2274

[8]. H. Lipson and H. Steeple (1970) Interpretation of X-ray Powder Diffraction Patterns [Macmillan, New York].

[9]. G.Selvarajan and C.K.Mahadevan (2006) J. Mater. Sci. 41, 8218-8225.

[10]. N.Neelakanda Pillai and C.K.Mahadevan (2007) Mater. Manuf. Processes 22, 393-399.

[11]. C.M.Padma and C.K.Mahadevan (2008) Physica B : Condensed Matter 403, 1708-1714.

[12]. R.Divya, M.Meena, C.K.Mahadevan and C.M.Padma (2014) Intl. J. Eng. Res. Appl. 4(5:5), 1 -7.

[13]. S.Goma, C.M.Padma and C.K.Mahadevan (2006) Mater. Lett. 60, 3701-3705.

[14]. N.Neelakanda Pillai and C.K.Mahadevan (2007) Mater. Manuf. Processes 22, 393-399.

[15]. M.Meena and C.K.Mahadevan (2008) Cryst. Res. Technol. 41, 166-172.

[16]. C.K.Mahadevan and K.Jeyakumari (2008) Physica B : Condensed Matter 403, 3990-3996.

[17]. J.M. Kavitha and C.K.Mahadevan (2013) Int. J. Eng. Res. Appl.(IJERA) 3(5), 1931-1940.

[18]. J.M.Kavitha and C.K.Mahadevan (2014) Spectrochim. Acta: Part A 128, 342-350.

[19]. R.S.S.Saravanan,D.Pugazhselvan \& C.K.Mahadevan (2012) J.Alloys and Compounds517,139-148

[20]. S.Boomadevi and Dhanasekaran R. (2004) J. Cryst. Growth 261, 70-76.

[21]. A.Vasudevan, S.Carin, M.R.Melloch and E.S.Hannon (1998) Appl. Phys. Lett. 73, 671.

[22]. C.K.Mahadevan (2008) Physica B : Condensed Matter 403, 57-60. 